\title{
¿Enterramientos tumulares en la edad del bronce? Nuevas evidencias para el Noroeste
}

\author{
Ramón Fábregas Valcarce
}

"Nacht und Nebel, niemand gleich!» Siehst du mich, Bruder? R. WAGNER: Das Rheingold (esc. III ${ }^{\mathrm{a}}$ )

\section{INTRODUCCIÓN}

El fenómeno megalítico peninsular -o tal vez tumular, a secas - es uno de los aspectos de la prehistoria reciente que ha sufrido las derivas más espectaculares dentro de la escala temporal, habiendo sido afectado profundamente por los vaivenes que ha experimentado la cronología absoluta y los sistemas de obtenerla en el período más próximo de la Prehistoria ${ }^{1}$.

En general, hasta los años 60 se postularán por parte de los especialistas -en especial los adscritos a la antes preponderante línea orientalista- unas cronologías bajas, deducidas a partir de la cronología comparada y las teóricas dependencias que se establecían con culturas del Mediterráneo oriental. De esta manera, las primeras construcciones megalíticas se elevarían en los albores de la Edad del Bronce, ya fuese muy a finales del $1 \mathrm{Il}^{\mathrm{er}}$ milenio o en los comienzos del $1 \mathrm{I}^{\circ}$, posición de la que discrepan Bosch Gimpera y otros occidentalistas, que favorecen un inicio más temprano para estas construcciones, mientras que los Leisner (1951) mantendrán una postura intermedia a raíz de su fundamental trabajo llevado a cabo en el concejo de Reguengos de Monsaraz ${ }^{2}$. La proliferación

\footnotetext{
Quiero dedicar este trabajo al Dr. Eduardo Ripoll Perelló, Catedrático de Prehistoria y Profesor Emérito de la UNED, cuyo constante apoyo y estímulo han sido fundamentales en mi carrera. En los momentos amargos vividos durante 1992, el valor de mi hermana Cristina y su indeclinable resolución de luchar contra una enfermedad mortal fueron para mí un espejo de conducta.

2 Una síntesis de las distintas posiciones hasta el año 1960, aunque desde una posición
} 
desde finales de los 60 de dataciones radiocarbónicas para monumentos megalíticos peninsulares y de otras zonas europeas produjo un vertiginoso retroceso en la cronología de éstos, contribuyendo decisivamente al desplome casi completo de las tesis orientalistas y resituando el fenómeno megalítico en unas coordenadas neolíticas o calcolíticas, fundamentalmente precampaniformes, al tiempo que se prestaba escasa atención a la posibilidad o evidencia de la perduración de estas formas de enterramiento en el curso de la Edad del Bronce.

En el caso del Noroeste peninsular, sobre el que nos vamos a centrar en el presente trabajo, durante mucho tiempo existirá un silencio casi total respecto a cuestiones de periodización o cronología, dentro de una aceptación más o menos implícita de las tesis evolucionistas y occidentalistas de Bosch Gimpera $(1932,1944)$. Habría que exceptuar de esta atonía las consideraciones que efectúa $G$. Leisner $(1938,61,65-66)$ en su añeja - pero todavía no superada en ciertos aspectos-Tesis Doctoral dedicada a las sepulturas megalíticas de Galicia y Norte de Portugal, proponiendo que éstas se encuadran fundamentalmente en el Cobre y el Bronce y rechazando asi abiertamente las tesis de Bosch de un origen antiguo de las cámaras simples en Tras-os-Montes. No será hasta fines de los 70 , cuando ya se comienza a disponer de un cierto número de dataciones para el Centro de Portugal, que se expone en una sintesis (RodRiguez $1979,109)$ la existencia de tres momentos dentro del magalítico gallego, abarcando desde un Neolítico final hasta los inicios de la Edad del Bronce, grosso modo entre el 3000-1800 a.C. en fechas radiocarbónicas ${ }^{3}$.

Este encuadre cronológico-cultural para el megalitismo del Noroeste pasa a predominar en los estudios de conjunto que se efectuan a ambas orillas del Miño, si bien con importantes matices por lo que se refiere al desarrollo interno de este fenómeno momumental, que se contempla, según los casos, de una forma más o menos unilinear o polimórfica (FA. BREGAS 1992, 37). Al mismo tiempo, la creciente disponibilidad de dataciones radiocarbónicas en el Noroeste dio lugar a una carrera hacia atrás que por algunos momentos parecía conducir el megalitismo regional al primer puesto en antigüedad, en función de algunas fechas sitas en la primera mitad del $V^{\circ}$ milenio, hoy en día consideradas dudosas (CHAN DA

inequivocamente orientalista, la dan Almagro y Arribas en su monografia sobre Los Millares (1963, 183-202). Más recientemente, Arribas y Molina (1984) han elaborado un nuevo estado de la cuesión.

3 Las fechas que manejaremos en este trabajo serán las correspondientes a la calibración del Carbono 14, salvo cuando se indique que se trata de cronología radiocarbónica o convencional. 
Cruz 1, Outeiro de Ante 3). En cualquier caso, la aplicación del Carbono 14 ha servido para anclar firmemente el inicio de este fenómeno en el último tercio del $\mathrm{V}^{\circ}$ milenio antes de Cristo (fines del $\mathrm{V}^{\circ}$ en fechas radiocarbónicas).

En cuanto al final del fenómeno tumular en el Noroeste, ha habido un consenso casi total entre los especialistas gallegos y del Norte de Portugal a la hora de situarlo en los albores del Bronce Antiguo, lo que tendria lugar en el último tercio del $1 l^{e r}$ milenio (hacia el 1800 a.C. aproximadamente en cronologías convencionales) (RODRiguez 1990, 72; JORGE 1991, 207) ${ }^{4}$.

Esta fase agónica vendría representada por cambios en las prácticas funerarias, implicando en unos casos la reutilización de grandes sepulcros de corredor, aunque prescindiendo de sus accesos monumentales originales (algo propuesto por los excavadores de Forno dos Mouros - CRIADo et al. 1991, 136- o Dombate -BEllo 1992-). Otras veces aparecen túmulos bajos, constituidos por piedras o no, albergando en su interior construcciones pétreas diversas (cistas, dólmenes, simples estelas) con una tendencia hacia la disminución de tamaño del recinto funerario, que en ocasiones llega a desaparecer como tal espacio estructuralmente definido.

Siguiendo, por tanto, la visión más aceptada sobre el fenómeno tumular en el Noroeste, las formas monumentales de enterramiento entrarían en crisis desde los inicios del Bronce Antiguo, en el último tercio del $\mathrm{II}^{\text {er }}$ milenio, al generalizarse la tendencia hacia la sepultura individual no visible sobre el paisaje, cuyo mejor representante serían las cistas excavadas en tierra conteniendo ricos ajuares metálicos tipológicamente encuadrables en el Bronce Inicial (VÁzQuez 1980). Con la desaparición de este tipo de tumbas, en los primeros siglos del $11^{\circ}$ milenio (i?), el Noroeste entraría en un res nullius por lo que a evidencia funeraria se refiere hasta la misma conquista romana, si exceptuamos el discutido caso de ciertas fosas excavadas en el suelo (FÁBREGAS y RUIZ -GÁLVEZ 1992) o el depósito de cerámicas del Bronce avanzado en algún túmulo (CALO y SiERRA 1983). Este panorama no es, por otro lado, exclusivo del Noroeste, sino que ha sido señalado en otros lugares de la fachada occidental de la Península para las etapas media y final del Bronce (RUIZ-GÁLVEZ 1990, 85; BELÉN et al. 1991; GoNZÁLEZ et al. 1992, 206).

4 No obstante, Cruz $(1992,93)$ propone en un reciente trabajo la existencia en la necrópolis tumular de Aboboreira (Oporto, Portugal) de una fase tardía que podría llegar hasta mediados del $11^{\circ}$ milenio. 
En nuestra opinión, la ausencia de tumbas reconocibles arqueológicamente en el Noroeste durante el $1{ }^{\circ}$ milenio puede deberse a varios factores como, por ejemplo, el recurso a formas alternativas al enterramiento para disponer de los cadáveres (v.g. inmersión en cursos de agua) no siempre valoradas suficientemente (BRADLEY y GoRDON 1988; BRADLEY $1990,108)$. Pero, sobre todo, en este trabajo plantearemos la posibilidad de que durante buena parte de esta etapa pervivan los enterramientos en túmulo, con unos ajuares funerarios poco significativos, lo que haría difícil la adscripción cultural de estas sepulturas con base en criterios exclusivamente arqueológicos. De hecho en un trabajo anterior (FÁBREGAS 1992, 267) hemos observado que en los momentos epigónicos del megalitismo, a fines del $1 \mathrm{II}^{\mathrm{er}}$ milenio, el ajuar (particularmente el material lítico) se hace a menudo escaso o poco característico y sólo la eventual presencia de especies cerámicas como el campaniforme o de algún elemento metálico permiten un encuadramiento del yacimiento más o menos firme. Siguiendo esta línea de razonamiento y a partir de las informaciones y dataciones proporcionadas por excavaciones recientes y de la reinterpretación de evidencias más antiguas, creemos verosímil que, al menos en ciertas zonas del Noroeste, se mantuviesen en boga durante gran parte del $11^{\circ} \mathrm{mi}-$ lenio formas de enterramiento tumulares, herederas en muchos aspectos - no el menor su integración en necrópolis cuya antigüedad se remonta a veces hasta el $V^{0}$ milenio- de la tradición megalítica.

\section{LA EVIDENCIA FUNERARIA: VALORACIÓN}

\section{Cuestiones previas}

Dado que los elementos de convicción a emplear consistirán básicamente en dataciones radiocarbónicas, es necesario efectuar algunas consideraciones generales de orden metodológico sobre la aplicación del Carbono 14 al fechado de monumentos tumulares. En efecto, esta clase de yacimientos presenta habitualmente una historia compleja tanto por lo que se refiere a la construcción como en función de su a veces dilatada utilización y las modificaciones/destrucciones sucesivas. Dejando al margen aspectos difíciles de valorar como la contaminación, la posible latitud cronológica de los carbones de origen vegetal o los aspectos técnicos del análisis efectuado en el laboratorio correspondiente -esto último más trascendental de lo que se cree-, uno de los factores a tener más en cuenta es el relativo a la ubicación precisa de las muestras datadas en cada caso.

- Los carbones procedentes del túmulo son particularmente problemáticos, ya que pueden llegar accidentalmente mezclados con las tierras 
en el curso del proceso de construcción, pero corresponder en realidad a actividades ajenas y anteriores a ésta: un ejemplo prototípico lo darían los cuatro análisis radiocarbónicos para el túmulo 3 de Outeiro de Ante (Baiâo, Oporto), con resultados a cual más dispar (JoRGE 1980, 63-64).

- Una perspectiva más alentadora la ofrecen los restos orgánicos recuperados en las capas subtumulares, pues a menudo pueden proporcionar una fecha post quem para la erección del monumento, a partir por ejemplo del análisis de los carbones originados en el curso de las labores de limpieza de la vegetación previas a la construcción. No obstante, tampoco estas muestras están exentas de problemas contextuales, pues los carbones muy dispersos pueden no estar relacionados con la actividad constructiva y ser bastante anteriores a ella; en otros casos se constata que la preparación del terreno conlleva la remoción del nivel superior del suelo original, dejando inmediatamente bajo el túmulo restos muy anteriores a éste. Un ejemplo muy ilustrativo de esta clase de peligros lo dan las fechas radiocarbónicas del suelo enterrado bajo la mámoa 1 de Châ de Carvalhal (Baiâo, Oporto) que en cotas distantes sólo $5 \mathrm{~cm}$ dieron unos valores separados por casi 1.000 años (CRUz 1992, 28).

- Un caso especial es el representado por las muestras procedentes del interior de estructuras arqueológicas como son las cámaras ortostáticas, los corredores o las fosas excavadas en el túmulos. Las cámaras tienen el defecto de que muy raramente constituyen verdaderos depósitos cerrados y o bien poseen una prolongada pervivencia, con lo que se puede estar fechando simplemente la última etapa de uso o, en el peor de los casos - si se recogen por ejemplo carbones dispersos-, se puede obtener en realidad una media correspondiente a diversas etapas de utilización de ese espacio, a lo que habría que añadir casi siempre por desgracia violaciones o intrusiones modernas. Otro tipo de estructuras, normalmente intactas, son menos proclives a esta clase de problemas: éste es el caso de ciertos pasillos de acceso recientemente excavados, como el de Campiños 6 que desde su oclusión final se mantuvo inalterado, permitiendo los carbones hallados sobre las piedras del relleno datar el cierre a comienzos del $1 \mathrm{II}^{\mathrm{er}}$ milenio (FÁBREGAS y FUENTE 1991-92, 131). Unas circunstancias semejantes se dan en las fosas secundarias detectadas en los túmulos, aunque debe recordarse que en éstos y otros casos las fechas obtenidas serán un término ante quem para el monumento en el que se integran.

Como ya señalábamos en una nota anterior, las fechas que vamos a manejar son las correspondientes a la calibración de los resultados radiocarbónicos, recurriendo a la curva promediada ventenal recientemente ampliada y revisada (PEARSON y STUIVER 1993). Nuestra opción se basa 
en dos argumentos: a) sólo la calibración permite -con todas sus limitaciones, desde luego- una aproximación a una cronología real; b) los distanciamientos temporales apreciables cuando se emplean dataciones convencionales se revelan a menudo poco significativos una vez aplicada la calibración. Hemos utilizado el intervalo total correspondiente a $2 \sigma$, por considerarlo más riguroso a la hora de comparar las distintas fechas, que por otra parte son todavía escasas (Fig. 1). Al mismo tiempo, a título orientativo, llevamos a cabo un análisis probabilístico correspondiente a la/s intersección/es efectuadas sobre la curva de calibración (AITKEN 1990, 103; BOWMAN 1990, 48; StUIVER y REIMER 1993, 226), seleccionando el segmento temporal que reúna una mayor probabilidad (no inferior al 66 por 100) (v. Cuadro 1). Un problema difícil de sortear es el de las desviaciones que en ciertos casos ( $\mathrm{v} . \mathrm{g}$. Piedrafita 5 ) son muy elevadas, anulando en buena medida la utilidad de las fechas obtenidas dado el amplio intervalo de calibración resultante.

Antes de entrar directamente a considerar los yacimientos tumulares objeto de nuestra atención, debemos aclarar que la definición cronológica del período en que nos moveremos - Edad del Bronce- es para el Noroeste tarea particularmente ingrata, puesto que la tradicional cronología (1800-700/600 a.C.) (VV.AA. 1979, 51; BLAS 1983, 237; EIROA y REY 1984, 47; JORGE 1988) se basa en paralelos metálicos de solvencia limitada, toda vez que, entre otros problemas, la práctica totalidad de estos hallazgos son casuales o descontextualizados y se dispone de un número todavía escaso de excavaciones o dataciones absolutas, por otra parte desigualmente distribuidas en la escala temporal ${ }^{5}$. En coherencia con nuestra opción de emplear las fechas de calendario obtenidas a partir de la calibración de los resultados radiocarbónicos procedentes de los yacimientos tumulares en cuestión, consideraremos el límite inferior para la Edad del Bronce propuesto en una síntesis reciente (GonzALEZ et al. 1992) que, con base en el C-14 calibrado, retrotrae éste hasta los inicios del último tercio del $1 I^{\text {er }}$ milenio. Por lo que respecta al final de esta gran etapa en el caso concreto del Noroeste, es muy verosímil que deba tam. bién ser llevado hacia atrás en el tiempo si tenemos en cuenta que en el poblado fortificado de Torroso (Mos, Pontevedra), un nivel con objetos de hierro en abundancia da unas fechas calibradas que se sitúan en los siglos VIII-VII a.C. (PEÑA 1992, 45).

Concentrándose básicamente en torno a los extremos superior e inferior de dicho intervalo cronológico (Fabregas y Ruiz-Galvez 1992, Figs. 2-3). 


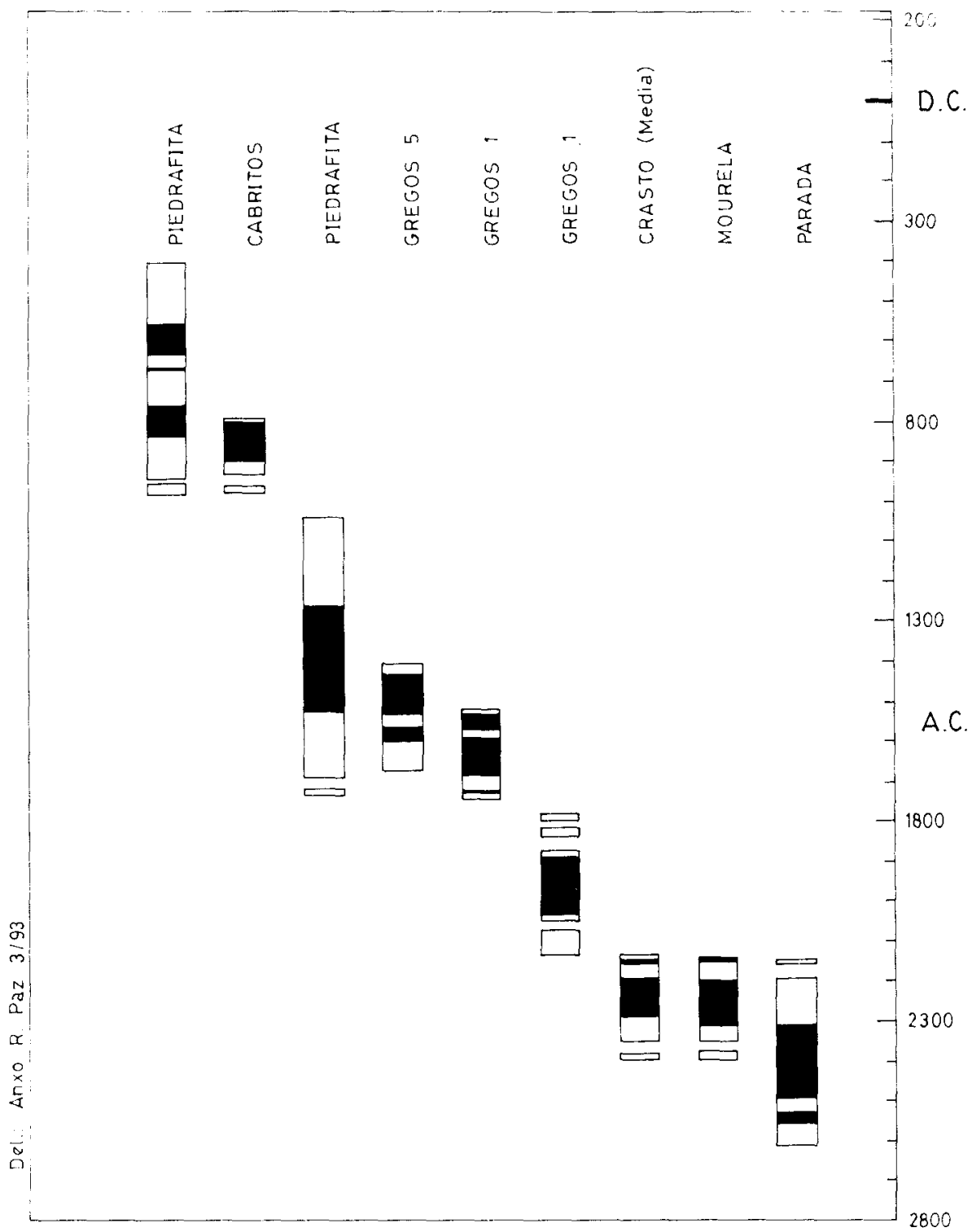

Fig. 1. Representación esquemática de las fechas calibradas incluidas en este trabajo. Las áreas oscuras coinciden con elllos intervalos/s para 1 o y las silueteadas con el (los) correspondiente/s a $2 \mathrm{o}$. 


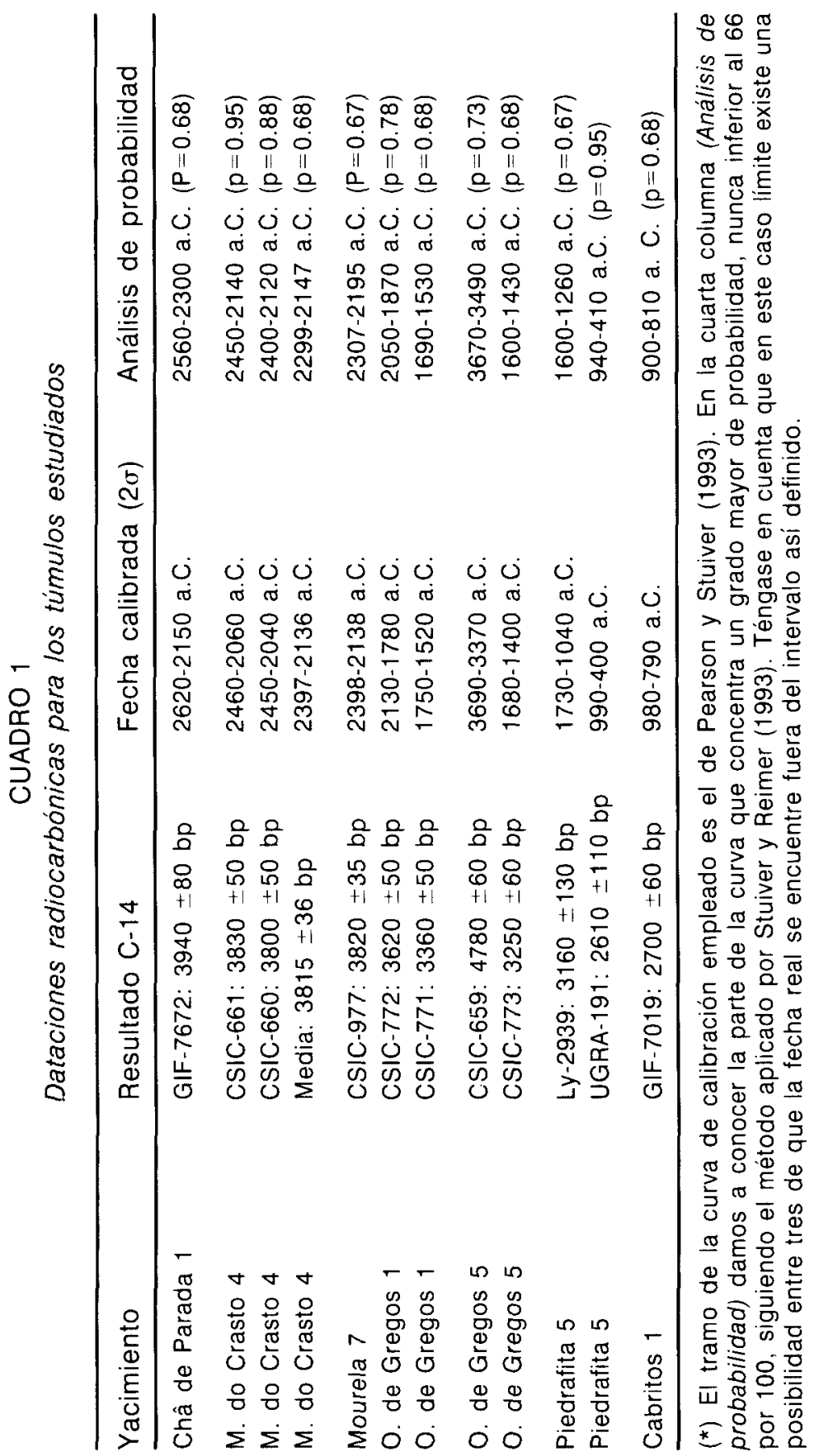


Catálogo de los yacimientos

Châ de Parada 1 (Baiâo, Oporto)

Se trata de un gran sepulcro de corredor complejo, recientemente excavado y para el que se dispone de un buen número de dataciones radiocarbónicas, fijando su construcción hacia la segunda mitad del IV ${ }^{\circ}$ milenio pero continuando en uso durante el III (JORGE y BETTENCOURT 1988; Cruz 1992, 92). La fecha que nos interesa aqui proviene de carbones localizados entre los intersticios de una estructura de cierre situada frente al corredor y puede señalar una fase terminal de utilización de este monumento megalítico, si bien dada la localización de la muestra analizada no debe descartarse totalmente la posibilidad de mezclas de materiales orgánicos de distinta antigüedad y por otra parte el resultado adolece de una desviación típica bastante elevada.

\section{Meninas do Crasto 4 (Baiâo, Oporto)}

Túmulo de tipo cairn (compuesto a base de piedras) de dimensiones pequeñas, cuya estructura ortostática central había sido destruida, pero a partir de las huellas conservadas se pudo deducir que ésta consistiría posiblemente en una cámara de reducido tamaño. Las muestras analizadas provienen de la parte superior del suelo enterrado bajo la construcción y un sencillo análisis indica que los resultados son estadísticamente idénticos (para un nivel de significación mayor del 95 por 100), por lo que hemos procedido a hallar la media ponderada de ambos (GUILLESPIE 1984, 30; AITKEN 1990, 112). Una tercera fecha (GAK-10943: 4220 \pm 140 bp) para ese mismo nivel, a pesar de su desviación típica elevadísima es estadísticamente diferente de las otras dos $y$, como otras suministradas por el mismo laboratorio para yacimientos del Noroeste, es considerada anómala (JoRGE 1983; 1985a).

\section{Mourela 7 (As Pontes, Coruña)}

Es un túmulo de grandes dimensiones conteniendo en su interior un dolmen poligonal cerrado de 2,3 $\mathrm{m}$ de diámetro en buen estado de conservación (MACIN̄EIRA 1929, 210) (Fig. 2). Según su explorador, éste se encontraba sin violar cuando fue abierto a comienzos de siglo hallándose en el piso de la cámara numerosos carbones y tierra calcinada, de los que se recogieron muestras, parte de las cuales han sido analizadas recientemente. El valor tabulado, aunque preciso, presenta el inconveniente de haber sido obtenido mediante la unión de dos muestras de carbón, con el consiguiente peligro de mezcla de restos cronológicamente dis- 

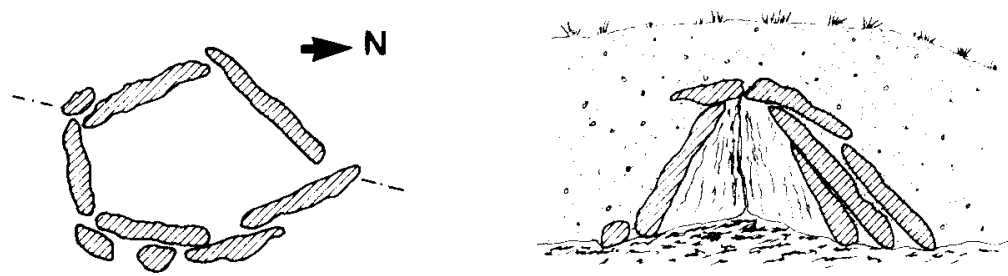

Del.: Anxo R. Paz 3/93

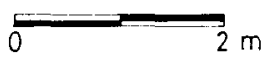

Fig. 2. Planta y sección de la cámara del túmulo 7 de A Mourela (según MarcinelRa 1929).

pares. Otro resultado $(258 \pm 26 \mathrm{bp})^{6}$ obtenido a partir de fragmentos de carbón de características muy diferentes a los anteriores corresponde bien a una intrusión de época moderna o, admitiendo el parecer de Maciñeira, a la penetración de tierras y otros restos en el curso de la apertura de la sepultura.

\section{Outeiro de Gregos 1 (Baiâo, Oporto)}

Al igual que Meninas do Crasto 4 , se trata de un túmulo de tipo cairn que cobijaba un dolmen poligonal bajo y de pequeño tamaño. Hacia el ESE se localizó una estructura de forma rectangular definida por piedras sobresaliendo verticalmente de la coraza exterior del monumento, asi como por una gran laja horizontal. Bajo esta última se localizaron sendas muestras de carbón que una vez analizadas proporcionaron unos resultados estadísticamente diferentes entre si (para un nivel de significación superior al 95 por 100). Dado que ambas fueron efectuadas en el mismo laboratorio esa disparidad se deberá en principio a motivos no instrumentales y el autor de la excavación favorece la más antigua de las fechas (JORGE et al. 1988, 98), tal vez a causa del gran número de raíces existentes en el área de donde se extrajeron las muestras (JORGE 1980, 24). Por nuestra parte, creemos que la contaminación moderna en muestras tan recientes no explica fácilmente esa divergencia tan acusada $(260 \pm 71$ años) ${ }^{7}$, la cual puede responder más bien al hecho de que esos carbones

6 Producto de la combinación de dos fechas estadísticamente idénticas, obtenidas a partir de muestras de carbón de las mismas características (CSIC-978: $250 \pm 30$ bp y CSIC-910: 280 $\pm 50 \mathrm{bp}$ ).

Mook y Waterbolk $(1985,53)$ señalan que para muestras no muy antiguas, la contaminación por materiales orgánicos modernos es poco relevante y por tanto las dataciones más recientes serán en principio las más significativas. 
representan actividades no contemporáneas, de orden ritual o incluso doméstico (se hallaron orificios de poste bajo las piedras), debiendo favorecerse entonces la datación más reciente para indicar el momento final de uso de la estructura mencionada y, quizás, del túmulo en su conjunto.

\section{Outeiro de Gregos 5 (Baiâo, Oporto)}

Túmulo de tipo cairn, bajo y de pequeñas dimensiones, que carecía al parecer de cualquier tipo de construcción interna (JoRgE 1982) (Fig. 3). De las tierras subyacentes al monumento se recuperaron diversas muestras de carbón que fueron sometidas a análisis radiocarbónicos (JORGE 1985b; 1988), planteando las dos dataciones obtenidas la misma problemática ya comentada para el túmulo 1 de la misma necrópolis, por lo que nos decantamos en principio por la más moderna de ellas. Es posible que los 1000 años de diferencia entre ambas fechas puedan deberse a la mayor profundidad de la muestra correspondiente al resultado CSIC$659(-0,70 \mathrm{~m})$ y asimismo hay que resaltar que la fecha CSIC-773 se obtuvo a partir de carbones recuperados en diversas cotas (entre $-0,45$ y $-0,70 \mathrm{~m}$ ), por lo que no es inverosímil que -excluyendo una contaminación moderna significativa- la erección del cairn se haya producido de hecho en un momento algo más tardío.

\section{Piedrafita 5 (Las Regueras, Asturias)}

Consistía en un túmulo de tierra de dimensiones considerables que, al igual que otros de la misma necrópolis, no albergaría construcción ortostática alguna, si bien en la parte media del monumento se documenta un círculo de piedras sueltas, aparentemente sin finalidad arquitectónica (BLAS 1985, 132). Las dos fechas radiocarbónicas disponibles se obtuvieron a partir de muestras procedentes de la misma zona, dentro de una gruesa capa de cenizas extendida por gran parte del túmulo y sellada por un nivel de tierras superpuesto. La elevada desviación típica de los resultados y la gran diferencia entre ambos (550 \pm 170 años) plantean serios problemas a la hora de efectuar una valoración arqueológica. Siendo las dos fechas estadísticamente distintas para un nivel de significación superior al 99 por 100, la combinación de ambas está fuera de cuestión y esa divergencia parece en principio difícil de explicar a través de procesos de contaminación, dada su magnitud y la localización de las muestras. Por otra parte, al contrario que en los casos anteriores, los análisis han sido efectuados por laboratorios diferentes y cabe contemplar, por tanto, la posibilidad de que esa disparidad se deba a razones instrumentales, 


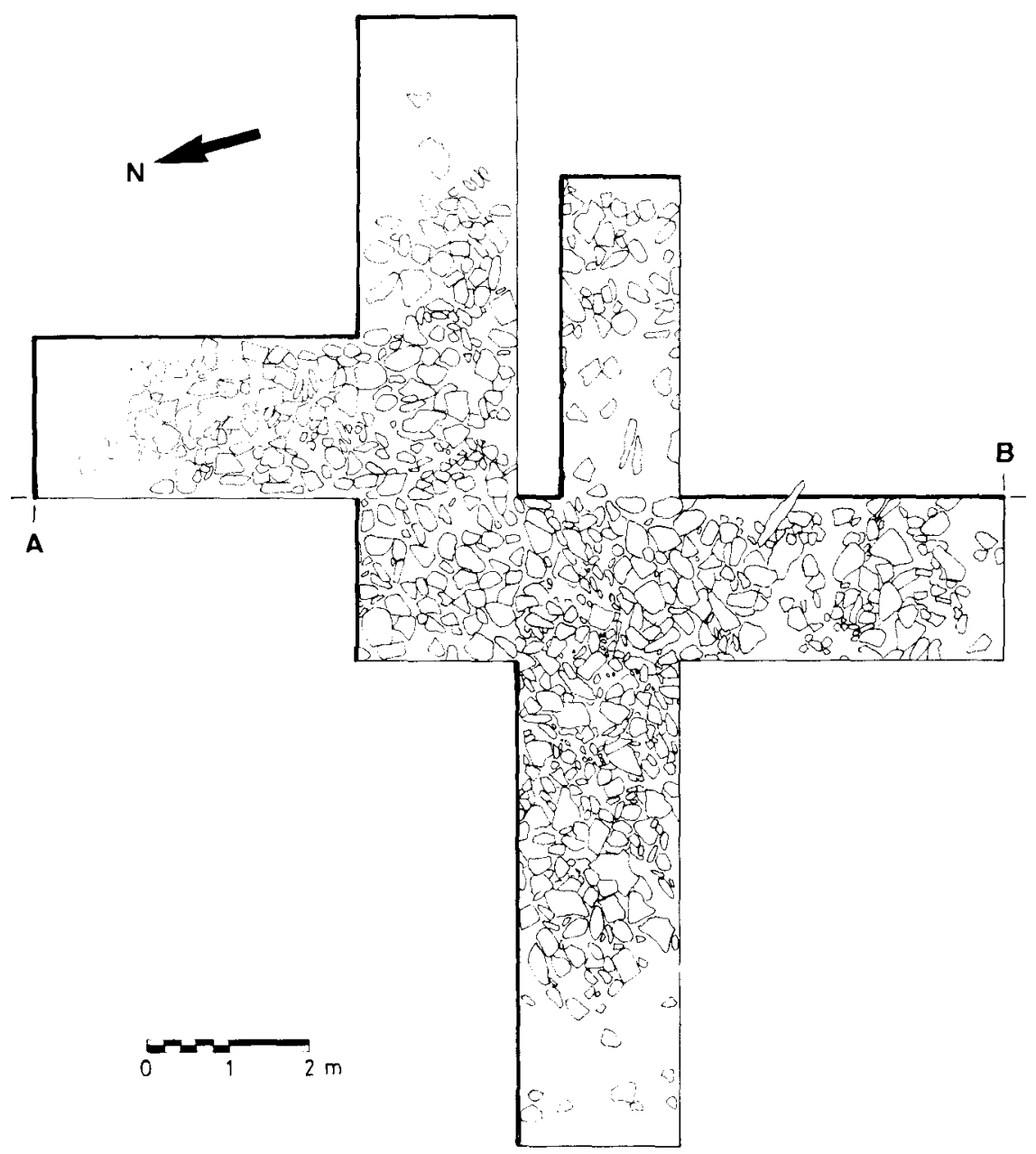

A

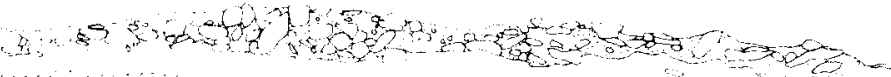

Del: Anxo R. Paz $3 / 93$

Fig. 3. Planta y corte NNE-SSW del túmulo 5 de Outeiro de Gregos (modificado a partir de JORGE 1982, Figs. 3-4). 
sin que dispongamos de indicios para optar por uno u otro resultado ${ }^{8}$. No obstante, con toda la prudencia que viene al caso, y mientras no se disponga de nuevas dataciones que sirvan para contrastar nuestra opinión, las razones arqueológicas nos inclinan a primar la fecha Ly-2939.

\section{Cabritos 1 (Amarante, Oporto)}

Se trataba de un pequeño túmulo de tierra, conteniendo un dolmen poligonal asimismo de reducido tamaño. A $1 \mathrm{~m}$ de este último se encontró una fosa elíptica excavada en el subsuelo $(1,8 \times 1 \mathrm{~m})$, parcialmente ladeada con piedras y rellena de tierra y carbones (JORGE y VILAÇA 1985). La única fecha para este monumento proviene de la fosa mencionada y nada indica arqueológicamente que aquella pueda ser anómala (JORGE $1988,124)$. Subsiste el problema de la articulación entre la fosa y el conjunto tumular, pues las zonas adyacentes al dolmen estaban revueltas; sin embargo dadas las características constructivas del túmulo, su localización topográfica y los materiales encontrados en la cámara y super-

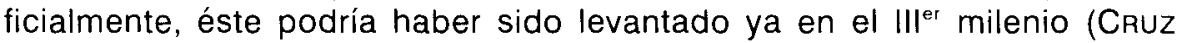
$1992,71)$, en tanto que la fosa habria sido excavada más de 1000 años después, al tiempo que quizás se efectuaban otras modificaciones en la parte central del monumento.

\section{ANÁLISIS}

Si cada una de las evidencias que hemos manejado en el apartado anterior suscita uno u otro tipo de dudas, el conjunto de ellas creemos que señala con claridad la persistencia de formas de enterramiento tumular a lo largo del $11^{\circ}$ milenio e incluso, de forma más dudosa, a comienzos del $1^{\circ}$. De todos modos, ya se tenía con anterioridad constatación arqueológica de actividades humanas en ciertos túmulos del Noroeste peninsular durante momentos avanzados de la Edad del Bronce, comprendiendo por ejemplo el depósito de vasos de ancho borde horizontal

$s \quad$ No es tarea que competa al arqueólogo efectuar juicios sobre la idoneidad del trabajo efectuado por uno u otro laboratorio de C-14, si bien la calidad de éstos no es idéntica (SCOTT et al., 1990). Sin embargo, el arqueólogo si debe valorar la posibilidad de errores sistemáticos o no en los resultados que recibe, contrastándolos en su caso. Un buen ejemplo de esta problemática lo dan las muestras procedentes de hogueras bajo un túmulo del Norte de Portugal, que analizadas por tres laboratorios distintos, revelaron el buen acuerdo entre dos de ellos -reforzándose mutuamente por lo tanto-, y la excesiva antigüedad de las fechas del tercero, que de otro modo habrian sido aceptadas sin discusión (com. pers. del Dr. Fernán Alonso). 
en fosas practicadas secundariamente en el túmulo (CALo y SiERRA 1983) o el -más problemático contextualmente hablando- hallazgo de cerámica de tipo Baiôes, arrojada al parecer en el curso de la violación de otro túmulo (KaLB y Hök 1979). En la Meseta Norte, Fabián $(1992,119)$ recoge un gran número de túmulos megalíticos con materiales del Bronce Medio-Final, terminando por afirmar que no se trata de intrusiones sin más y que en esta zona se da una apreciable continuidad por lo que al enterramiento se refiere entre el Calcolítico y el Bronce avanzado. El interés de las noticias que ahora manejamos para el Noroeste estriba sin embargo en el hecho de que en ciertos casos (v.g. Piedrafita 5 y Gregos 5) parece documentarse en momentos tardios del ${ }^{\circ}{ }^{\circ}$ milenio la construcción y no simplemente la reutilización - o saqueo- de túmulos, a veces con rasgos todavía relativamente arcaizantes ${ }^{9}$.

A menudo se contrasta el carácter individual y la variabilidad de las formas sepulcrales a partir de mediados del $\left.1\right|^{\text {er }}$ milenio con el sesgo comunitario y homogéneo de las sepulturas megalíticas anteriores. Creemos que esta oposición debe matizarse en buena medida, pues las excavaciones de los últimos 10 años nos proporcionan la visión de un fenómeno megalítico recurriendo a diversas alternativas en el plano constructivo, al tiempo que se advierte la presencia de enterramientos individuales (Pena Mosqueira 3 - - SÁNCHES 1987) en el seno de un mundo funerario predominantemente colectivo. Es muy posible que al igual que se señala en la Meseta Norte (DELIBES 1988, 236; FABIÁN 1992, 117), estas tendencias individualizadoras en el apartado sepulcral se hiciesen más patentes hacia la $1 .^{a}$ mitad del $11^{\mathrm{er}}$ milenio (Vilafría 1 y 2 , ¿mamoa do Barreiro? -FABREGAS 1992) y sobre esta dinámica preexistente incidiría el campaniforme a partir de mediados de ese milenio, no tanto significando una ruptura sino más bien interactuando y adaptándose a los procesos sociales en curso.

La heterogeneidad ya mencionada afecta tanto a las soluciones constructivas - tipo de túmulo o de estructura central- como a la cultura material depositada en las sepulturas. Por una parte comentábamos al principio que al menos una parte de los grandes monumentos megalíticos (Forno dos Mouros, Châ de Parada 1, Dombate) deben haber continuado en la segunda mitad del $11^{\text {er }}$ milenio como puntos focales de actividad ritual ${ }^{10}$, evidenciando el peso de una tradición que posiblemente comen-

y Este mismo fenómeno se observa con mayor claridad aún en el curso de rigurosas excavaciones llevadas a cabo en la comarca de As Pontes (Coruña), las cuales indican la construcción de túmulos bien dentro de la 2. mitad del $11^{\circ}$ milenio a.C. Agradecemos al director de estas actuaciones, J. Vaquero Lastres, las informaciones suministradas sobre estos hallazgos.

10 El dolmen de Mourela 7 puede ser otro ejemplo de esta utilización de túmulos con es. 
zará a ser manipulada por determinados segmentos de la sociedad que llevan a cabo en esos lugares enterramientos, los cuales por su ubicación o carácter suponen de hecho un desmarque respecto a las pautas consagradas por el tiempo.

Esa misma tensión entre cambio y tradición puede observarse claramente en el túmulo de Châ de Carvalhal (Baiâo, Oporto), ejemplarmente excavado y publicado (Cruz 1992), el cual aúna las innovaciones de orden constructivo y ritual con el mantenimiento de caracteres arcaicos, en un momento a caballo entre el Calcolítico final y el Bronce Antiguo (Fig. 4). En efecto, este monumento presenta una ingente masa tumular, protegida por una coraza de piedra bien estructurada y con un anillo lítico medial, características todas que remiten a túmulos del IV milenio, y al mismo tiempo la cámara se configura como un dolmen de dimensiones pequeñas y planta rectangular en línea con las formas sepulcrales de la Edad del Bronce. También el ajuar traduce esa ambivalencia, incluyendo elementos más o menos comunes como algunas cerámicas lisas junto a productos de prestigio, como campaniformes de varios tipos o puñales y puntas de cobre arsenical. Significativamente, los artefactos metálicos aparecieron en sendas fosas practicadas en el curso de la construcción del túmulo, mientras las cerámicas proceden de la cámara - fuertemente violada- 0 de sus inmediaciones. Este mutuo alejamiento del metal y el campaniforme evoca la frecuente disociación de estas dos clases de objetos en diversos contextos sepulcrales del Noroeste. Por otro lado, el depósito de materiales tan valiosos como las puntas Palmela o los puñales de espigo durante la elaboración del túmulo sugiere la importancia simbólica de esta tarea para el colectivo responsable de ejecutarla, que va más allá del mero enterramiento de uno de sus miembros junto a algunos elementos de ajuar.

Construcciones de tipo cairn como Meninas do Crasto 4 u Outeiro de Gregos 1 señalan ya un alejamiento más decidido de las formas megalíticas clásicas, tanto por lo que se refiere a las soluciones técnicas como a la neta pérdida de monumentalidad, en momentos que si bien pueden retrotraerse a los finales del $1 I^{\text {er }}$ milenio alcanzan posiblemente los siglos XVII-XVI a.C. El reducido tamaño de la cámara -cuando la hay-y la aparición en ese recinto de elementos de adorno personal en materiales preciosos como las pulseras de plata, apuntan tal vez hacia una individualización y diferenciación social aún más acentuadas dentro de esas

tructuras ortostáticas de cierto porte, pero las condiciones de su descubrimiento aconsejan prudencia. 


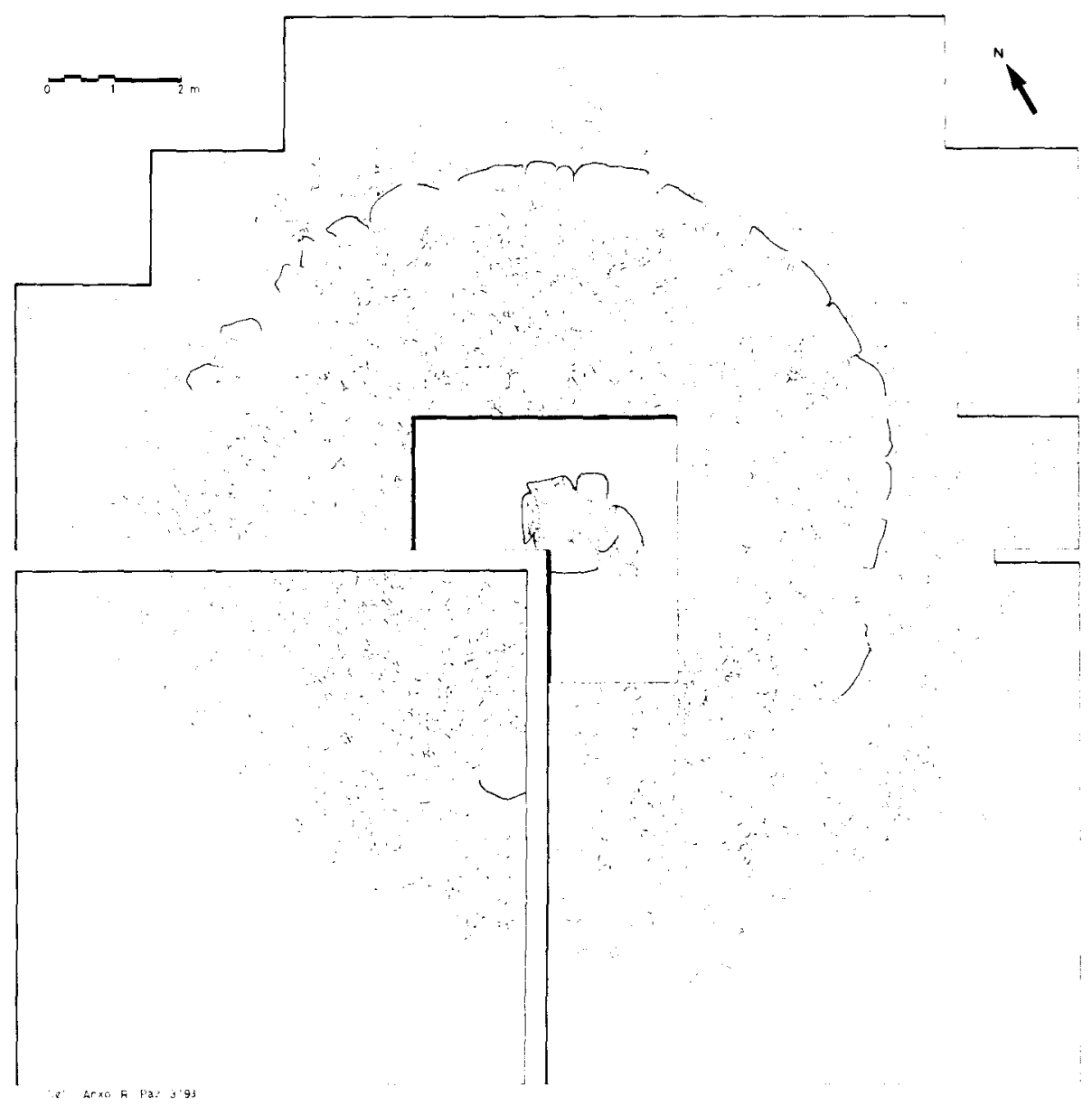

Fig. 4. Planta de Châ de Carvalhal 1 (a partir de Cruz 1992, Figs. 9 y 10). 
comunidades. Hacia mediados del $11^{\circ}$ milenio se advierte un cambio importante, pues aunque se mantiene el referente tumular (al menos en ciertas zonas del Noroeste), parecen eclipsarse definitivamente los recintos ortostáticos (cairn de Outeiro de Gregos 5), eventualmente reemplazados por otras soluciones constructivas: fosas conteniendo carbones $u$ otras señales de fuego (Cabritos 1) o una simple delimitación del área central del túmulo mediante un círculo lítico basal (Piedrafita 5). La implementación de estas fórmulas arquitectónicas puede llevarse a cabo modificando o reutilizando monumentos preexistentes (Cabritos 1, imámoa 87 de Serra Faladora? (FÁBREGAS y SUÁREZ 1991, 198) o bien levantando éstos ex novo (Piedrafita V, Gregos 5). Al mismo tiempo los ajuares se hacen muy parcos y escasamente diagnósticos, desapareciendo todos los elementos normalizados, metálicos o cerámicos, presentes con anterioridad. Sería caer en un burdo evolucionismo lineal el considerar esta clase de sepulturas como exclusivas de etapas avanzadas del Bronce en el Noroeste, pues estas soluciones «paramegalíticas» pueden aparecer con anterioridad en momentos que se remontan al $11^{\text {er }}$ milenio o incluso antes: tal sería el caso de La Cruz del Muertu (Las Regueras, Asturias), donde bajo una gran masa tumular aparece un simple empedrado basal asociado a una industria lítica de características arcaicas (BLAS 1990, 76), o los probablemente más tardíos túmulos 16 y 18 de Campiello (Tineo, Asturias), que a pesar de su buen tamaño no albergaban en su parte central otra cosa que pequeños espacios enlosados y pozos con cenizas (Fig. 5), acompañados de escasísimo material lítico ${ }^{11}$. Sin embargo, a la vista de las evidencias disponibles, se puede avanzar la hipótesis de que a lo largo del $11^{\circ}$ milenio los túmulos paramegalíticos irian ganando predicamento de forma progresiva hasta llegar a ser los únicos construidos, lo que no obstaría para la eventual reutilización de monumentos más antiguos (con o sin transformación de éstos), fenómeno que podría llegar hasta pleno Bronce Final como sugieren la fecha de la fosa de Cabritos 1 o el hallazgo de vasos de ancho borde horizontal en sendos depósitos secundarios efectuados en el túmulo 5 de Marco do Camballón (Vila de Cruces, Pontevedra) (CAlo y Sierra 1983, 67; Fuente 1988, 97). Cabe preguntarse, por último, si las mudanzas de orden estructural en los sepulcros tumulares, así como la repetida aparición de capas de carbón o pozos con cenizas no estarán relacionados con un cambio parejo hacia

Nótese que la escasez de materiales no se debe a las sempiternas violaciones, pues las áreas descritas fueron halladas intactas y debidamente documentadas (JORDA et al., 1972-73). Asimismo puede destacarse la aparición “in situ" en el túmulo 16 de un cincel de pizarra, un tipo de artefacto repetidamente asociado en el Noroeste peninsular a mazas o dobles hachas con cronologías en torno a la segunda mitad del III milenio (FABREGAS 1992a). 
a)

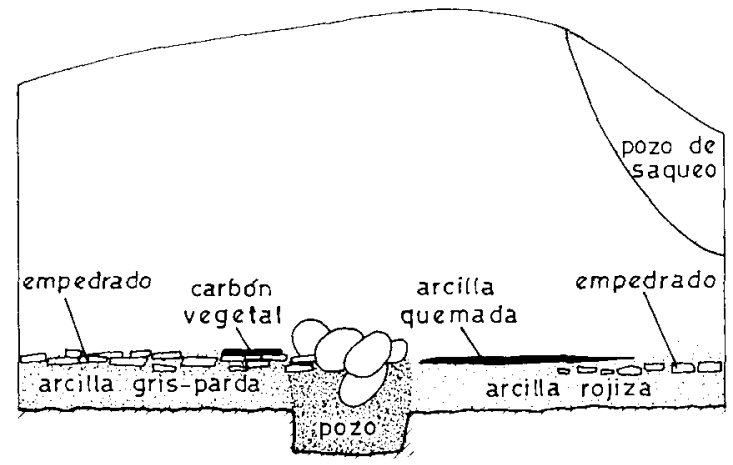

b)

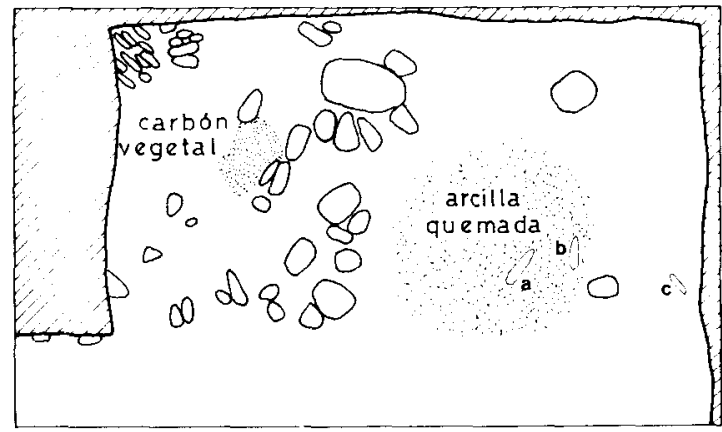

$\stackrel{N}{4}$

c)
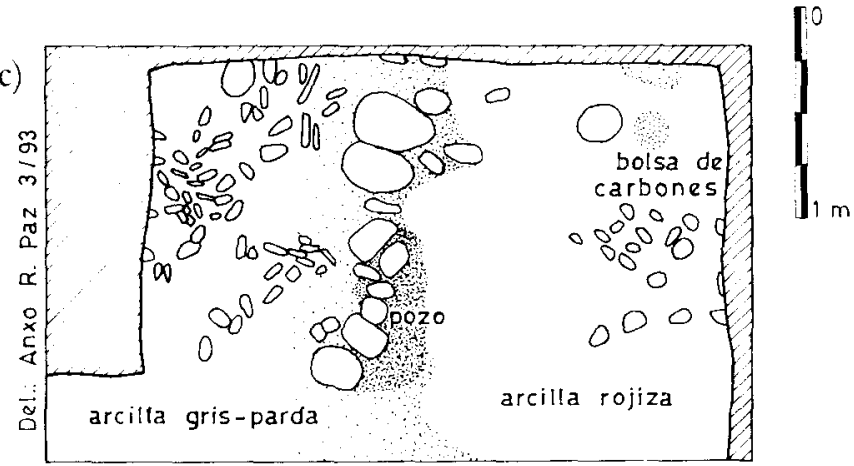

Fig. 5. Túmulo 16 de Campiello: zona central (según Jordá et al., 1972-73, Fig. 5). A) Sección W-E, B) Planta a 1,7 $\mathrm{m}$ de profundidad (a: cincel; b: azuela; c: hoja de silex). C) Planta a 1,8 $m$ de profundidad. 
prácticas de incineración (JoRDÁ et al. 1972-73, 148), por otra parte presentes ya en un enterramiento infantil en cista de Gandón (Cangas, Pontevedra) atribuido a la transición Calcolítico-Bronce Antiguo (PEÑA 1985 y com. pers.)

Si se admite la posibilidad que hemos venido apuntando de una pervivencia de sepulturas tumulares durante buena parte del $11^{\circ}$ milenio, habrá que plantearse las razones del "empobrecimiento" de los ajuares funerarios y la consecuente opacidad por lo que respecta a su precisa adscripción cultural. Para explicar este fenómeno, detectable en diversos lugares de Europa, se habla a menudo de una crisis en los modelos subsistenciales y una reorientación de los fundamentos sociopolíticos, conduciendo eventualmente a un período de menor diferenciación social (Burgess 1980, 79; Cruz 1992, 116). De esta forma, la parquedad de la información funeraria podría relacionarse con un paralelo ocaso de la intensificación agraria detectable durante la segunda mitad del $1 \mathrm{I}^{\mathrm{er}}$ milenio en diversas zonas del Noroeste, el cual se hace manifiesto desde comienzos del $11^{\circ}$ milenio a través de la escasez y pobreza material de los asentamientos, circunstancias que parecen mantenerse hasta fines del Bronce, cuando comienzan a aparecer poblados fortificados (CARBALLo y FÁBREGAS 1991). Diversos autores consideran el eclipse habitacional en distintas áreas del Occidente de Europa durante buena parte de la Edad del Bronce como consecuencia de diversos factores, entre ellos la crisis en el modelo de explotación de la tierra que no permitiría tras un lapso de tiempo la permanencia de la población en un mismo lugar, en tanto no se generalizasen una serie de técnicas y cultígenos (BRADLEY 1984, 91; Ruiz-Gálvez 1990, 93).

Sin negar la trascendencia de estas alteraciones en el sistema subsistencial y sus posibles repercusiones en el campo funerario, creemos que sería demasiado simple establecer una relación de causa a efecto entre ambos fenómenos. Después de todo hay que recordar que los ajuares prestigiosos recuperados de cistas y túmulos o grandes tesoros como el de Caldas de Reyes no parecen corresponderse con una paralela complejidad por lo que se refiere a las esferas doméstica o productiva, si bien en diversas áreas del Noroeste se detecta al menos desde mediados del III ${ }^{\text {er }}$ milenio una extensión de las redes de intercambio a través de las cuales se obtienen materias primas exóticas o muy localizadas (v.g. sílex, variscita, metal) (SÁNCHES 1989, 450; JoRgE 1986, 255), pero también información que puede estar detrás de la expansión de elementos dotados de contenido simbólico cuyo control podría ser utilizado como medio de legitimación por parte de determinados segmentos de la sociedad (cerámica campaniforme, armas y adornos de metal, mazas y bipennes de piedra pulida). A partir del 1600-1500 a.C. podría producirse un cambio 
en los rituales funerarios que aún conservando el referente legitimador del túmulo, incorporarían una disociación entre el individuo y su "persona social» conllevando la desaparición de elementos valiosos en el ajuar, cuyo potencial de ostentación sería sustituido tal vez por un ceremonial más dilatado y complejo, ligado a la elaboración del túmulo o la deposición del cadáver (BARRETT 1990, 186). Es posible incluso que el significativo rol jugado por las armas de metal pasase a ser interpretado en otras arenas, como el arte rupestre al aire libre (petroglifos) o los depósitos en medios acuáticos. En relación con esta última propuesta podemos citar la sugerencia de BARRETT y NEEDHAM (1988, 133), los cuales consideran que en ciertos casos puñales del Bronce Antiguo avanzado fueron arrojados a los ríos en vez de llevarlos a las sepulturas, como parte de un extenso proceso de deposiciones votivas vinculadas con el ritual funerario.

\section{ABSTRACT. - BRONZE AGE BARROWS? NEW EVIDENCE FOR THE NORTHWEST OF THE IBERIAN PENINSULA}

To this day, the chronology of the funerary mounds in the Northwest was usually thought to span roughly from the second half of the $\mathrm{V}^{\text {th }}$ millenium BC to the later part of the III $^{\text {rd }}$ BC (in calendar dates), when the traditional mounds would be superseded by another type of funerary structure like the typical Early Bronze Age cists dug into the soil. The excavations of the last 10 years in Galicia, Asturias and Northern Portugal have given us a new glimpse on the later stages of the mound tradition that seems to last longer than previously reckoned, taking into account radiocarbon dates of some tombs (Cuadro 1) pointing firmly to their building even in the second half on the $2^{\text {nd }}$ millenium BC. These relics of a longstanding mound tradition show interesting features: they are generally of smaller size and there are no orthostatic chambers and we find instead a varied set of structures - a single standing stone, pits containing ashes mixed with earth and stones, stone circles delimiting a central area underneath the mound-, other times older barrows are reused with or without alterations of the previous construction. Although the evidence is by no means clear, there could be a case for a shift from inhumation to cremation practices, while everywhere the exotic items formerly found in the tombs of the Early Bronze Age give way to more impoverished, scarcely diagnostic grave assemblages. These changes in mortuary practices have been viewed in the light of an alleged crisis in the socio-economic framework during the greater part of the $2^{\text {nd }}$ millenium $B C$, though we feel that shifts in the strategies of social reproduction could be responsible as 
well, removing the display of exotica (vg. metallic items) from funerary contexts to other arena like rock art or river deposits.

\section{BIBLIOGRAFIA}

Almagro, M. y ARribas A. (1963): “El poblado y la necrópolis megalíticos de Los Millares», Bibliotheca Praehistorica Hispana 3, Madrid

AITKEN, M. J. (1990): Science-based Dating in Archaeology. Londres.

ARribas, A. y MoLINA, F. (1984): "Estado actual de la investigación del megalitismo en la Península Ibérica", Scripta Praehistorica F. Jordá Oblata. Salamanca, págs. 63-112.

BARRET, J. C. (1990): "The monumentality of death: the character of Early Bronze Age mortuary mounds in southern Britain", World Archaeology, 22,2, págs. 179-189.

BARRETT, J. C. y NEEDhAM, S. P. (1988): "Production, circulation and exchange: problems in the interpretation of the Bronze Age bronzework", in (J. C. Barrett y I. A. Kinnes (eds.) The Archaeology of Context in the Neolithic and Bronze Age: Recent Trends. Sheffield, págs, $127-$ 140.

Belen, M. Escacena, J. L. y Bozzino, M. I. (1991): “El mundo funerario del Bronce final en la fachada atlántica de la Península Ibérica», Trabajos de Prehistoria, 48, págs. 225-256.

Bello Dieguez. J. M. (1992): “Grabados, pinturas e idolos en Dombate (Cabana, La Coruña). ¿Grupo de Viseu o grupo Noroccidental? Aspectos taxonómicos y cronológicos"; Seminario o Megalitismo no Centro de Portugal. Mangualde (en Prensa).

Blas Cortina, M. A. de (1983): La prehistoria reciente de Asturias. Oviedo.

- (1985): "Piedrafita $V$. Nuevos aspectos sobre el polimorfismo de las arquitecturas funerarias prehistóricas en el N-NO de la Península ibérica», Arqueología, 12, págs. 129-136.

- (1990): «Excavaciones arqueológicas en la necrópolis megalítica de La Cobertoria (divisoria Lena-Quirós) y en los campos de túmulos de Piedrafita y El Llanu la Vara (Las Regueras)". Excavaciones Arqueológicas en Asturias 1983-86, págs. 69-77. Oviedo.

Bosch Gimpera, P. (1932): Etnología de la Peninsula Ibérica. Barcelona.

- (1944): El poblamiento antiguo y la formación de los pueblos de España. México.

BOWMAN, S. (1990): Radiocarbon dating. Londres.

BRADLEY. R. (1984): The social foundations of prehistoric Britain. London.

- (1990): The passage of arms. An archaeological analysis of prehistoric hoards and votive deposits. Cambridge.

Bradley, R. y Gordon, K. (1988): "Human skulls from the River Thames, their dating and significance», Antiquity, 62, págs, 503-509.

BuRgess, C. (1980): The Age of Stonehenge. Londres.

CALO F. \& SIERRA, X. C. (1983): "As orixenes do castrexo no Bronce Final", in G. Pereira (ed.) Estudos de Cultura Castrexa e de Historia Antiga de Galicia. Santiago de Compostela, págs. 19-86.

Carballo Arceo, X. \& Fabregas Valcarce, R. (1991): "Dataciones de Carbono 14 para castros del Noroeste peninsular", Archivo Español de Arqueologia, 64, págs. 244-264

Criado BoAdo F. (dir.) (1991): «Arqueología del Paisaje El área Bocelo-Furelos entre los tiempos paleolíticos y medievales", Arqueoloxíl/nvestigación, 6. Santiago de Compostela.

Cruz, D. J. da (1988): "O megalitismo do Norte de Portugal", Trabalhos de Antropologia e Etnologia, 28 , págs. 15-41

- (1992): A Mamoa 1 de Châ de Carvalhal (Serra da Aboboreira). Coimbra, Instituto de Arqueologia.

Delibes DE CASTRO, G. (1988); “Enterramiento calcolítico en fosa de "El Ollar", Donhierro (Segovia)", Espacio, Tiempo y Forma, 1, págs. 227-238.

Eiroa, J. J. y Rey, J. (1984, Guia de los petroglifos de Muros. Muros.

FabIÁn Garcia, J. F. (1992): «El enterramiento campaniforme del túmulo 1 de Aldeagordillo (Ávila)", Boletin del Seminario de Estudios de Arte y Arqueologia, págs. 97-132.

Fábregas Valcarce, R. (1992): Megalitismo del Noroeste de la Peninsula lbérica. Tipología y secuencia de los materiales líticos. Madrid. 
- (1992a): «Nuevos útiles perforados del interior de Galicia: una reflexión sobre el momento epimegalítico", Espacio, Tiempo y Forma, 5, págs. 265-280.

Fabregas Valcarce. R. y Fuente andrés, F. (1991-1992): “Excavación da mámoa 6 de Os Campiños (Leiro, Rianxo). Campaña de 1984", Brigantium, 7, págs. 91-149.

Fábregas Valcarce. R. y Ruiz-Gálvez Priego. M. (1992): “Funerary \& domestic domains in the prehistory of the NW Iberian Peninsula", Social life and social change: The Neolithic of NorthWestern Europe. Glasgow.

Fábregas Valcarce, R. y Suárez Otero, J. (1991): "Mámoa 87 de Serra Faladora: un túmulo megalítico del Norte de Galicia", Espacio, Tiempo y Forma, 4, págs. 193-218.

FUENTE ANDREs. F. de la (1988): "El material cerámico", in R. Fábregas Valcarce y F. de la Fuente Andrés, Aproximaciones a la cultura material del megalitismo gallego, págs. 73-154. Santiago de Compostela.

GILLESPIE, R. (1984): Radiocarbon user's handbook. Oxford.

Gonzalez MARCEN. P. et alii (1992): Arqueología de Europa, 2250-1200 a.C. Una introducción a la "Edad del Bronce». Madrid.

JoRdÁ CERDÁ.F. et alii (1972-1973): "Notas sobre los túmulos dolménicos de Campiello (Tineo) y su edad postdolménica", Zephyrus, 23-24, págs. 131-152.

JoRGE, S.O. (1986): Povoados da Pré-história recente da regiâo de Chaves-V $P^{a}$ de Aguiar. Oporto, Instituto de Arqueología.

- (1988): "Reflexóes sobre a Pre-História recente do Norte de Portugal». Trabalhos de Antropologia e Etnologia, 28, págs. 85-112.

JoRGE, V.O. (1980): “Escavaçâo da mamoa 1 de Outeiro de Gregos", Portugalia, 1, págs. 9-27.

- (1982): "A mamoa 5 de Outeiro de Gregos, um "tumulus" nâo megalítico da Serra da Aboboreira", Arqueologia, 6, págs. 32-39.

- (1983): "Escavaçâo das mamoas 2 e 4 de Meninas do Crasto", Arqueologia, 7, págs. 23-43.

- (1985a): "Novas dataçôes de radiocarbono para mamoas do concelho de Baiâo", Arqueologia, 11, págs. 182-183

- (1985b): "Uma dataçâo pelo radiocarbono para a Mamoa 5 de Outeiro de Gregos", Arqueologia, 12, págs. 94-95.

- (1988): "Datas de Carbono 14 para a mamoa de Châ de Parada 4", Arqueologia, págs. 121124.

- (1991): "Necrópole pré-histórica da Aboboreira (Distrito do Porto). Uma hipótese de diacronia", Homenagem a Santos Júnior. Lisboa, págs. 205-208.

JoRGE,V. O. y VILAÇA, R. (1985): "As mamoas de Cabritos", Arqueologia, 11, págs. 51-66.

Jorge. V. O., Alonso. F. y DelibriAs, G. (1988): "Novas datas de Carbono 14 para mamoas da Serra da Aboboreira", Arqueologia, 18, págs. 95-99

KALB, P. y HoCK, M. (1979): "Escavaçôes na necrópole de mamoas Fonte da Malga", Beira Alta, 38, págs. 595-604.

LEISNEA, G. (1938): Verbreitung und Typologie der galizisch-nordportugiesischen Megalithgräber. Marburg.

LEISNer, G. y V. (1951): Antas do concelho de Reguengos de Monsaraz. Lisboa, Instituto para a Alta Cultura.

MACINEIRA. F. (1929): "Notable grupo de círculos líticos y túmulos dolménicos de la cuenca superior del Eume", Arquivos do Seminario de Estudos Galegos, 2, págs. 197-230.

MOOK, W. G. y WATERBOLK. H. T. (1985): Radiocarbon dating. Estrasburgo.

Pearson. G. W. y Stuiver. M. (1993): “High-precision bidecadal calibration of the radiocarbon time scale 500-2500 BC", Radiocarbon, 35, págs. 25-33.

Peña Santos, A. (1985): "Las cistas de Gandón (Cangas de Morrazo, Pontevedra)", El Museo de Pontevedra, 39, págs. 79-94.

- (1992): "Castro de Torroso (Mos, Pontevedra)". Arqueoloxía/Memorias, 11. Santiago de Compostela.

Rodriguez CASAL, A. A. (1979): "O Megalitismo na Galiza. A sua problemática e o estado actual

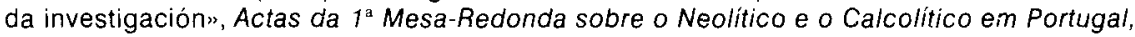
págs. $103-115$.

- (1990): “Die Megalithkultur in Galicien», Probleme der Megalithgräberforschung. Berlin, págs. 53-72. 
Ruiz-Gálvez Priego. M. (1990): “Canciones del muchacho viajero", Veleia, 7, págs. 79-103. SANCHES. M. de J. (1987): "A mamoa 3 de Pena Mosqueira", Arqueologia, 15, págs. 94-115.

- (1989): "Breve síntese do povoamento pré-histórico no planalto mirandês", Revista da Faculdade de Letras, 6, págs. 445-453.

ScotT, E. M. et alii (1990): "An overview of all three stages of the international radiocarbon intercomparison", Radiocarbon, 32, págs. 309-319.

Stuiver, M. y ReImer. P. J. (1993): “Extended 14C database and revised CALIB radiocarbon calibration program", Radiocarbon, 35, págs. 215-230

Vazouez Valera, J. M. (1980): "Enterramientos en cista de la Edad del Bronce en Galicia", Pontevedra, 0, págs. 23-40.

WV.AA. (1979): Prehistoria e Arqueoloxia de Galicia. Estado da cuestión. Lugo. 